\title{
Can secular trends in child growth be estimated from a single cross sectional survey?
}

\author{
Carlos A Monteiro, Alberto M Torres
}

\begin{abstract}
Objective-To formulate and evaluate a new method to measure secular trends in child growth based on the cross sectional collection of heights of children and young adults.

Design-Trends in child growth obtained from comparison of two national surveys made with an interval of 15 years were compared with estimates obtained from comparison of height deficits of children and young adults in the more recent survey. Setting-Brazil.

Subjects-Random sample of children (6 and 7 years old) and young adults (21 and 22 years old) living in Brazil in 1974 and 1989 (a total of 23271 subjects in 1974 and 5479 in 1989).

Main outcome measures-Increments in average heights of 6 and 7 year old children in a 15 year period.

Results-Mean height of 6 year old children increased $4.0 \mathrm{~cm}$ (boys) and $3.3 \mathrm{~cm}$ (girls) from 1974 to 1989 . Similar results were obtained by subtracting, in the 1989 survey, mean height deficits found at ages 21 and $6(3.8 \mathrm{~cm}$ for males and $3.5 \mathrm{~cm}$ for females). Positive changes in the mean height of 7 year old children could also be predicted by subtracting, in the 1989 survey, height deficits found at ages 7 and 22.
\end{abstract}

Conclusions-Findings of this study support the hypothesis that secular trends in child growth can be estimated by comparing height deficits observed in children and young adults.

\section{Introduction}

Physical growth in children is one of the best indicators of overall health and wellbeing of a population.' Secular trends in child growth are of primary importance in determining the impact of general social and economic changes, as well as of specific public health interventions. ${ }^{2}$ However, reliable information on trends in child growth is rarely available, and most often it does not include data from the countries where malnutrition is most widespread. Reviewing the databank on anthropometry existing at the World Health Organisation, ${ }^{3}$ we found that only a few developing countries have two or more comparable cross sectional surveys that would permit an assessment of temporal trends in child growth. What is known from the epidemiology of stunting may suggest, as we propose in this article, an alternative and simpler approach to assessing the evolution of child growth.

The course of stunting in developing countries is relatively well known for the first years of life. On the basis of results from 22 longitudinal and semilongitudinal studies, Waterlow found that linear growth in these countries begins to fall off in the second three months of life and remains at about $80 \%$ of reference values until the second or third year; from there, and up to 5 years of age, growth increments are not substantially different from those observed in developed countries. ${ }^{4}$ Only four studies in developing countries have followed child growth through older ages, including adolescence..$^{5-8}$ Nevertheless, all of these studies point to the same general finding: weight gain and the rhythm of growth after childhood can be very different from what is observed in healthy and well nourished populations (lower weight gain, later puberty, and lower peak height velocity), but total height gain from 5 years of age to adulthood is remarkably similar to reference values. An extension in the period of the adolescent growth spurt, which seems to be proportional to the degree of stunting that occurred during childhood, is seen as the main mechanism that prevents further deterioration in growth. ${ }^{7}$

If there is little change after childhood in the height retardation established early in life, a strong parallel could be expected between the average height deficits of children after their fifth birthday and their average deficits as adults. Then a single, population based survey that includes a sample of school age children (say 5 to 7 years old) and a sample of young adults (say 20 to 25 years old) could provide useful information on trends in child growth over a 15-20 year period. Two anthropometric surveys representative of the entire Brazilian population (children and adults) and separated by 15 years provide a unique opportunity to test this proposition.

\section{Methods}

The federal agency responsible for demographic census and yearly multipurpose household surveys (Instituto Brasileiro de Geografia e Estatistica) conducted two large national surveys within a 15 year period, the first from August 1974 to August 1975 and the second from June to September 1989 (they will be referred to as the 1974 and 1989 surveys). Both surveys used multiple stage clustering and stratified sampling with adequate sample size ( 55000 households in 1974, or $0.25 \%$ of total households in the country, and 14000 households in 1989 , or $0.05 \%$ of total households in the country) to represent the five Brazilian macroregions and both rural and urban populations. Training, equipment, and methods for data collection were similar in the two surveys. Detailed methodology of the surveys has been described elsewhere. ${ }^{9}$

To test the hypothesis that growth retardation at 6 or 7 years of age and at adulthood was similar, we assumed that children aged 6 or 7 in the 1974 sample represented the same cohorts as did young adults aged 21 or 22 in the 1989 survey. That assumption is reasonable because mortality is rare among older children and young adults and the effect of migration in and out of the country is negligible.

In total, eight groups specific for age and sex were considered. They represented four "population 


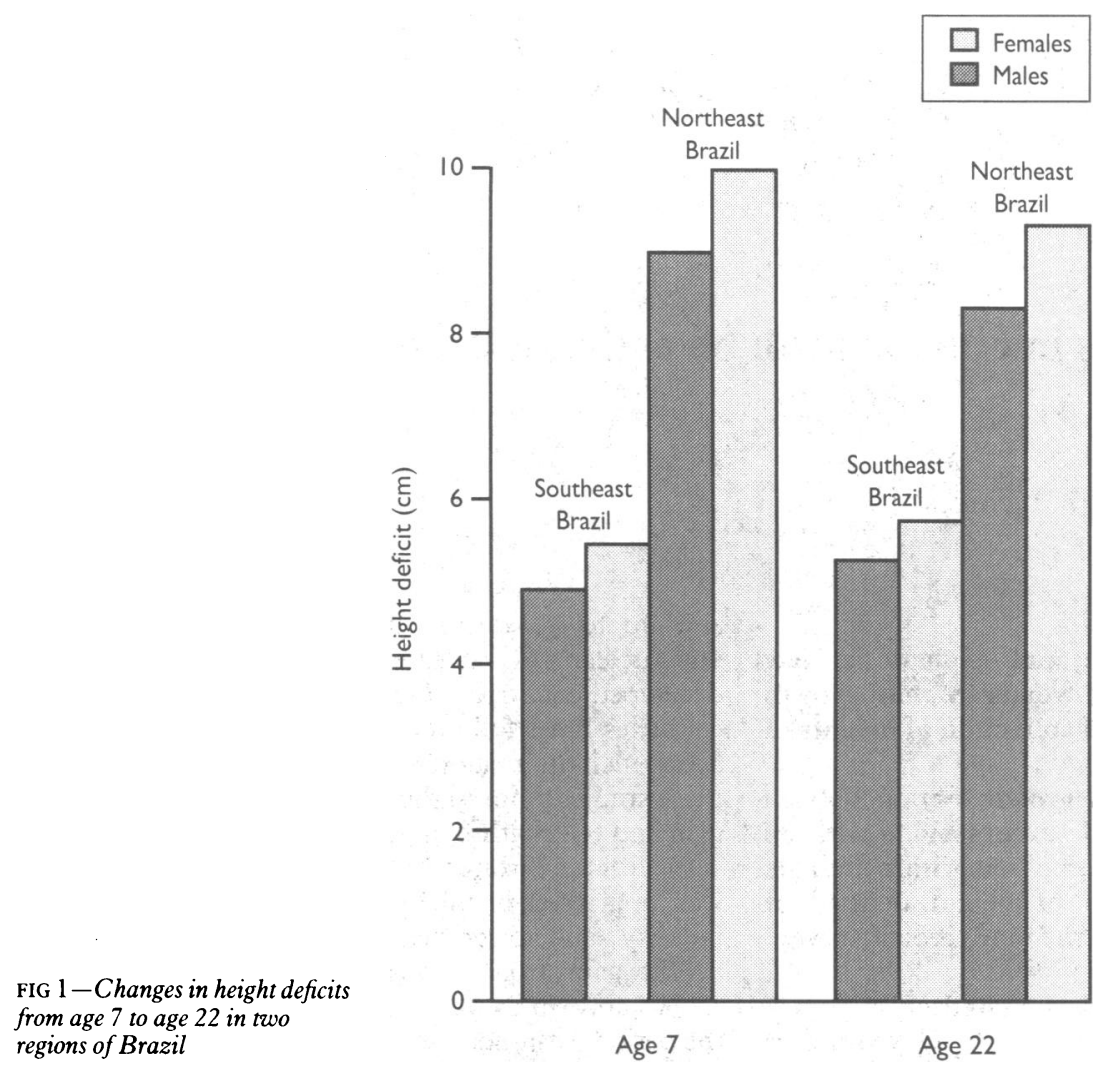

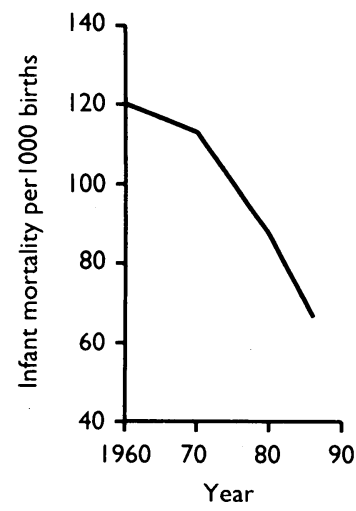

FIG 2-Infant mortality in Brazil.

Source: FIGBE/Unicef ${ }^{2}$

cohorts": males and females aged 6 in the 1974 survey (and aged 21 in 1989), and males and females aged 7 in 1974 (and aged 22 in 1989). Mean (SE) height and height deficits were calculated for the eight groups in the two surveys. Height deficits were computed by subtracting observed mean heights from age and sex specific reference heights. Reference heights were taken from the National Center for Health Statistics/ World Health Organisation standard, ${ }^{10}$ but similar results were obtained using the Dutch standard. ${ }^{1}$

Secular trends in child growth were estimated by subtracting mean heights of children of the same age groups and sex in the two surveys (1974 and 1989) and also by subtracting, in the most recent survey, mean height deficits found in young adults and children.

\section{Results}

Table I shows mean heights and height deficits for children aged 6 and adults aged 21 in the two surveys.

TABLE I-Heights and height deficits at ages 6 and 21 in two national surveys, Brazil

\begin{tabular}{lcclcc}
\hline & \multicolumn{2}{c}{ Males } & & \multicolumn{2}{c}{ Females } \\
\cline { 2 - 3 } \cline { 5 - 6 } & Age 6 years & Age 21 years & & Age 6 years & Age 21 years \\
\hline 1974 Survey: & & & & & \\
Mean $($ SE) height $(\mathrm{cm})$ & $111 \cdot 7(0 \cdot 1)$ & $168 \cdot 4(0 \cdot 2)$ & & $111 \cdot 4(0 \cdot 1)$ & $156 \cdot 4(0 \cdot 2)$ \\
Height deficit $(\mathrm{cm})$ & $7 \cdot 3$ & $8 \cdot 4$ & & $6 \cdot 2$ & $7 \cdot 3$ \\
Sample size & 3651 & 2194 & & 3660 & 2107 \\
1989 Survey: & $115 \cdot 7(0 \cdot 2)$ & $169 \cdot 7(0 \cdot 3)$ & & $114 \cdot 7(0 \cdot 2)$ & $157 \cdot 3(0 \cdot 3)$ \\
Mean $($ SE) height $(\mathrm{cm})$ & $3 \cdot 3$ & $7 \cdot 1$ & & $2 \cdot 9$ & $6 \cdot 4$ \\
Height deficit $(\mathrm{cm})$ & 821 & 569 & & 747 & 576 \\
Sample size & & & & & \\
\hline
\end{tabular}

TABLE II - Heights and height deficits at ages 7 and 22 in two national surveys, Brazil

\begin{tabular}{lccccc}
\hline & \multicolumn{2}{c}{ Males } & & \multicolumn{2}{c}{ Females } \\
\cline { 2 - 3 } \cline { 5 - 6 } & Age 7 years & Age 22 years & & Age 7 years & Age 22 years \\
\hline 1974 Survey: & & & & & \\
Mean (SE) height (cm) & $117 \cdot 0(0 \cdot 1)$ & $168 \cdot 2(0 \cdot 2)$ & & $116 \cdot 8(0 \cdot 1)$ & $156 \cdot 1(0 \cdot 2)$ \\
Height deficit $(\mathrm{cm})$ & $7 \cdot 4$ & $8 \cdot 6$ & & $6 \cdot 7$ & $7 \cdot 6$ \\
Sample size & 3721 & 2190 & & 3497 & 2251 \\
1989 Survey: & $120 \cdot 4(0 \cdot 2)$ & $169 \cdot 5(0 \cdot 3)$ & & $120 \cdot 3(0 \cdot 2)$ & $157 \cdot 3(0 \cdot 3)$ \\
Mean (SE) height $(\mathrm{cm})$ & $4 \cdot 0$ & $7 \cdot 3$ & & $3 \cdot 2$ & $6 \cdot 4$ \\
Height deficit $(\mathrm{cm})$ & 875 & 535 & & 803 & 553 \\
Sample size & & & &
\end{tabular}

In both males and females, height deficits at age 6 in 1974 were similar to height deficits at age 21 in 1989. The positive changes in child growth observed in the 15 years between the two cross sectional surveys $(4 \cdot 0$ $\mathrm{cm}$ for males and $3.3 \mathrm{~cm}$ for females) could be fairly accurately estimated simply by subtracting, in the most recent survey, height deficits found at ages 21 and $6(7 \cdot 1 \mathrm{~cm}-3.3 \mathrm{~cm}=3 \cdot 8 \mathrm{~cm}$ for males and $6.4 \mathrm{~cm}-$ $2.9 \mathrm{~cm}=3.5 \mathrm{~cm}$ for females).

Table II shows findings related to cohorts of children aged 7 in 1974 and adults aged 22 in 1989 . Once more, height deficits of children aged 7 in 1974 were similar to the height deficits of their "cohort" 15 years later. Once again, secular trends in the height of 7 year old children could have been fairly well estimated from the 1989 survey.

The existence in Brazil of deeper regional differences permits an evaluation of the single survey approach in populations exposed to different degrees of poverty. Figure 1 shows the "progression" of height deficits of children 6 and 7 years of age to adulthood in the two most populated and contrasting Brazilian regions: the "poor" northeast and the "rich" southeast. It can be seen that neither the "higher" height deficits found in the northeast (around $10.0 \mathrm{~cm}$ ) nor the "lower" deficits found in the southeast (around $5.0 \mathrm{~cm}$ ) changed substantially at adult ages. The small differences $(+0.4$ in the southeast and -0.6 in the northeast) are compatible with the traditional migration from the northeast to the southeast regions.

\section{Discussion}

If our findings are confirmed in other studies a practical alternative for assessing trends in child growth would be available immediately, either by including a sample of young adults in household anthropometric surveys or by adding height measurements of parents in surveillance systems based on height measurements of children entering primary school.

It is interesting to note that the same subtraction of height deficits at ages 21 and 6 and at ages 22 and 7, when applied to the 1974 survey, gives much lower values (around $1.0 \mathrm{~cm}$ instead of the 3.0 or $4.0 \mathrm{~cm}$ observed with the most recent survey). That value is similar to the secular trend that can be calculated by subtracting the height of adults 21 or 22 years of age in 1974 and from that of those in 1989. Apart from reinforcing the single survey approach, this indicates that recent trends in child growth in Brazil may represent an acceleration of secular trends. Indirect evidence that recent trends in health and nutrition determinants were more favourable than past trends is also found in trends in infant mortality (fig 2).

The question remains of whether children with retarded growth could grow at even higher rates and therefore have smaller height deficits as adults than as children. To answer that question more empirical evidence and a better understanding of the factors and mechanisms that drive growth after childhood is needed.

1 United Nations, Administrative Committee on Coordination/Subcommittee on Nutrition. Appropriate uses of anthropometric indices in children. Geneva: United Nations, 1990

2 Van Wieringen JC. Secular growth changes. In: Falkner F, Tanner JM, eds. Human growth. Vol 2. Postnatal growth. New York: Plenum, 1978:445-73. 3 World Health Organisation. Global nutrition status. Anthropometric indicators. Update 1989. Geneva: WHO, 1989.

4 Waterlow JC. Observations on the natural history of stunting. In: Linear growth retardation in less developed countries. New York: Nestle, 1988. (Nutrition Workshop Series No 14.)

5 Hauspie RC, Das SR, Preece MA, Tanner JM. A longitudinal study of the growth in height of boys and girls of West Bengal (India) aged six months to 20 years. Ann Hum Biol 1980; 7:429-41.

6 Billewicz WZ, McGregor IA. A birth-to-maturity longitudinal study of heights and weights in two West African (Gambian) villages, 1951-1975. Ann Hum 
7 Satyanarayana K, Radhaiah G, Murali Mohan B, Thimmayamma BVS, Pralhad Rao N, Narasinga Rao BS. The adolescent growth spurt of height among rural Indian boys in relation to childhood nutritional background: a 18 year longtidudinal study. Ann Hum Biol 1989;16:289-300.

8 Martiorell R, Rivera J, Kaplowitz $\mathrm{H}$. Consequences of stunting in early childhood for adult body size in rural Guatemala. Annales Nestle 1990;48: $85-92$

9 Monteiro CA, D'Aquino Benicio MH, Iunes RF, Gouveia NC, Taddei JAAC, Cardoso MAA. Nutritional status of Brazilian children: trends from 1975 to 1989. Bull WHO (in press).
10 Dibley MJ, Goldsby JB, Staehling NW, Trowbridge FL. Development of normalized curves for the international growth reference: historical and technical considerations. Am f Clin Nutrition 1987;46:749-62.

11 Eveleth PB, Tanner JM. Worldwide variation in human growth. New York: Cambridge University Press, 1976.

12 FIBGE/Unicef. Perfil estatistico de criancas e maes no Brasil. Mortalidade infantil e saude na decada de 80. Rio de Janeiro: Instituto Brasileiro de Geografia Estatistica, 1989

\title{
Effect of maintenance chemotherapy in childhood on numbers of melanocytic naevi
}

\author{
Elizabeth A Baird, Pamela M McHenry, Rona M MacKie
}

\begin{abstract}
Objective-(a) To determine whether children given chemotherapy for haematological malignancy have significantly more melanocytic naevi than age matched children in the local population; $(b)$ to establish whether any observed variation in naevus counts from normal is seen at the start of maintenance chemotherapy.

Design-Follow up of 29 consecutive children starting maintenance chemotherapy, with parental interview and count of all melanocytic naevi $\geqslant 2 \mathbf{~ m m}$ on the child's skin. Assessment repeated three years later after completion of maintenance chemotherapy. Other dermatological problems identified at either visit were also recorded.
\end{abstract}

Setting-Royal Hospital for Sick Children, Glasgow.

Results-At the start of maintenance chemotherapy all children had total body counts of melanocytic naevi within the normal range established for age matched children in the local population. Three years later total body naevus counts were significantly increased, the median increase being 66 naevi per child (95\% confidence interval 57 to 94$)$. The only other problem noted in these children was relatively poor regrowth of scalp hair.

Conclusion-Children on maintenance chemotherapy for haematological malignancies develop an excessive number of melanocytic naevi. Excessive numbers of melanocytic naevi are the most important risk factor for melanoma in the general population. These children should have periodic skin examinations at their follow up visits, and both child and parent should be educated about clinical features of early melanoma.

\section{Introduction}

While modern chemotherapy and radiotherapy regimens for childhood haematological malignancies are becoming increasingly successful in inducing long term remissions sequelae of such regimens are slowly being elucidated. Hughes $e t a l^{1}$ and de Wit $e t a l^{2}$ have reported a larger number of melanocytic naevi in children who have undergone chemotherapy for haematological malignancies compared with children who have not received chemotherapy. As the design of their studies was retrospective, however, it was not possible to determine whether the high naevi counts were present before chemotherapy and possibly associated with a phenotype also predisposed to develop haematological malignancy.

We decided to answer this question with a prospective study, counting naevi in children over a three year period at the start of and after maintenance chemotherapy, in order to quantify any changes in counts of melanocytic naevi. Other dermatological problems identified at the start or completion of chemotherapy were also recorded.

\section{Patients and methods}

In 1988, 29 children were enrolled in the study. All were undergoing treatment for a childhood haematological malignancy. The majority of children $(n=25)$ had acute common type lymphoblastic leukaemia. Of the remaining four children, two had acute $T$ cell lymphoblastic leukaemia, one acute myeloid leukaemia, and one Hodgkin's disease. The child with Hodgkin's disease and one with $\mathrm{T}$ cell leukaemia had a marrow transplant. The majority of the children were receiving the United Kingdom acute lymphoblastic leukaemia trial (UKALL 10) chemotherapy regimen, which consists of an initial induction course with vincristine, prednisolone, daunorubicin, and asparaginase. Intrathecal methotrexate is also given. After induction cranial irradiation is given. Maintenance therapy is continued for two years with monthly courses of vincristine and prednisolone, weekly methotrexate, and daily mercaptopurine.

The children's naevi were not counted at the time of diagnosis while they were undergoing induction chemotherapy for several reasons. Full skin examination is difficult when children are acutely unwell and less mobile than usual owing to illness and peripheral and central lines. In addition, we thought it inappropriate to ask parents to allow their children to participate in this study at such a sensitive time. They were therefore first assessed at the start of maintenance chemotherapy.

Parents were asked about specific dermatological problems encountered, including episodes of severe sunburn and any family history of multiple naevi or of malignant melanoma. The children were examined by looking specifically at hair growth, nails, and skin. A count of all melanocytic naevi $\geqslant 2 \mathrm{~mm}$ on the entire body surface was undertaken.

The children were reviewed three years later by using the same questionnaire and total body naevi recounted. At that time exposure to natural ultraviolet light was assessed by asking about holidays taken in the United Kingdom and abroad. Seven of the children were not assessed at the three year follow up. Three had died, three were geographically inaccessible, and one parent declined.

Naevus counts before and after chemotherapy were compared with numbers of naevi previously recorded in healthy children in the same age range, from the same geographical area. These children had their naevi counted either while attending for a routine school medical examination or while attending the outpatient department for minor ocular problems or viral warts. ${ }^{3}$ 